\title{
Rede Social de Apoio Durante Transições Familiares Decorrentes do Nascimento de Filhos ${ }^{1}$
}

\author{
Maria Auxiliadora Dessen ${ }^{2}$ \\ Marcela Pereira Braz \\ Universidade de Brasília - UnB
}

\begin{abstract}
RESUMO - O suporte da rede de apoio é fundamental à família e ao indivíduo no enfrentamento de transições normativas e não normativas no processo de desenvolvimento. Este estudo descreve as transformações nessa rede durante transições decorrentes do nascimento de filhos. Quinze pais de classe social baixa e suas respectivas esposas/companheiras, subdivididas em dois grupos (A: mães grávidas; B: mães com bebês de até seis meses), participaram de uma entrevista semiestruturada e responderam um questionário. A principal alteração na rede, segundo as mães, foi o aumento do apoio psicológico recebido; para os pais, foi o aumento da ajuda financeira e material. O apoio do marido/companheiro foi considerado, por todas as mães, mais importante que os demais. Os dados sugerem que, para compreender as alterações na rede social de apoio e no envolvimento do pai na vida familiar durante transições decorrentes do nascimento de filhos, é preciso conhecer as relações desenvolvidas entre os subsistemas familiares e o contexto social no qual as famílias estão inseridas.
\end{abstract}

Palavras-chave: rede social de apoio; família; nascimento de filhos; mãe e pai; avós.

\section{Social Support Network During Family Transitions to Parenthood}

\begin{abstract}
The social support network is essential to the individual and his/her family when they face normative and non-normative transitions throughout the developmental process. This article aims to describe the alterations in the family network during transitions to parenthood due to the birth of babies. Fifteen working class fathers and their wives/partners from two groups (A: Pregnant mothers; B: Mothers with babies aged from one to six months) answered a questionnaire and a guide of a semi-structured interview. According to the mothers, the increase of psychological support was considered the main alteration in the network; to the fathers, it was the increase of financial and material help. All mothers reported that the most important support came from their husbands or partners. Our data suggest that it is necessary to know about the relationships between the family subsystems and the social context in which the families are embedded in order to better understand the alterations in the social support network and in the father's engagement in the family during transitions to parenthood.
\end{abstract}

Key words: social support network; family; birth of babies; mother and father; grandparents.

Atualmente, a família vem sendo compreendida como um sistema complexo, composto por vários subsistemas (por exemplo, pai-mãe, irmão-irmão, genitores-filhos) que estão em constante interação, influenciando e sendo influenciados uns pelos outros (Dessen, 1994, 1997; Feiring \& Lewis, 1978; Minuchin, 1985, 1988; Trost, 1995). Além de toda a dinâmica de funcionamento interno da família, vários outros sistemas fora da família exercem importante influência nas interações e no desenvolvimento dos membros familiares, como a escola, o local de trabalho, a vizinhança, a comunidade e a rede social. Portanto, é fundamental que se estude a interdependência e a mútua influência dos processos intra e extrafamiliares (Bronfenbrenner,

1 Este trabalho contou com o apoio do CNPq. Agradecemos a colaboração de André Moniz e Giovana Carla de Sousa na coleta de dados.

2 Endereço: Universidade de Brasília-UnB, Instituto de Psicologia/PED, Laboratório de Desenvolvimento Familiar, Campus Universitário Darcy Ribeiro, Brasília- DF. CEP: 70.910-900. E-mail: dessen@unb.br
1986, 1996). Neste artigo, focalizamos a rede social de apoio das famílias, que vem sendo destacada como um dos fatores responsáveis pela manutenção do equilíbrio e da dinâmica familiar, principalmente durante períodos de transição decorrentes do nascimento de filhos (Dessen, 1997; Kreppner, 1992; Kreppner, Paulsen \& Schuetze, 1982).

\section{Rede social: definição e características}

Rede social é um sistema composto por “...vários objetos sociais (pessoas), funções (atividades dessas pessoas) e situações (contexto)" (Lewis, 1987, p. 443-444), que oferece apoio instrumental e emocional à pessoa, em suas diferentes necessidades. Apoio instrumental é entendido como ajuda financeira, ajuda na divisão de responsabilidades, em geral, e informação prestada ao indivíduo. Apoio emocional, por sua vez, refere-se à afeição, aprovação, simpatia e preocupação com o outro e, também, a ações que levam a um sentimento de pertencer ao grupo (Craig \& Winston, 1989). 
Várias são as pessoas que oferecem suporte à família e ao indivíduo, promovendo, assim, uma melhoria na qualidade de vida daqueles beneficiados (Brito-Dias, 1994; Ferreira, 1991; Lewis, 1987). Dentre elas, destacam-se os próprios membros familiares, outros parentes da família extensa (avós, tios, primos), amigos, companheiros, vizinhos e profissionais, que podem auxiliar de diversas maneiras: (a) fornecendo apoio material ou financeiro, (b) executando tarefas domésticas, (c) cuidando dos filhos, (d) orientando e prestando informações e (e) oferecendo suporte emocional.

Os suportes sociais recebidos e percebidos pelas pessoas são fundamentais para a manutenção da saúde mental; para o enfrentamento de situações estressantes, como tornar-se pai ou cuidar de alguém doente por muito tempo; para o alívio dos estresses físico e mental; e para a promoção de efeitos benéficos nos processos fisiológicos relacionados aos sistemas cardiovascular, endócrino e imunológico (Basic Behavioral Science Task Force of the National Advisory Mental Health Council, 1996; Uchino, Cacioppo $\&$ Kiecolt-Glaser, 1996). Hashima e Amato (1994) analisaram os dados de 1.035 dos 13.000 respondentes do Levantamento Nacional de Famílias e Atividades Domésticas (NSFH), realizado pelo Instituto de Pesquisa Social da Universidade de Temple, no período de 1987-1988. Esses autores encontraram uma relação significativa entre suporte social percebido e renda familiar, isto é, o suporte percebido foi negativamente associado com relatos de comportamentos punitivos dos genitores em relação aos filhos, principalmente em famílias de baixa renda. $\mathrm{O}$ auxílio recebido da rede também foi negativamente correlacionado com relatos dos genitores de emissão de comportamentos de não apoiar os filhos. Portanto, o suporte social diminui a probabilidade de ocorrência de comportamentos disfuncionais (punitivos e/ou não-apoiadores) em famílias de diferentes níveis sócio-econômicos, sendo particularmente benéfico para genitores provenientes de classes sociais menos favorecidas.

Os suportes sociais são, também, fatores importantes para a adequação dos comportamentos maternos em relação aos filhos. Crittenden (1985), visando estudar as correlações entre as redes sociais, a qualidade do cuidado da criança e o desenvolvimento infantil, observou 121 díades mãe-criança, através do procedimento da "Situação Estranha", utilizado em estudos sobre a relação de apego. Os resultados mostraram que os padrões maternos de suporte social estavam relacionados com a segurança da criança nas relações de apego. Jennings, Stagg e Connors (1991) também encontraram efeitos benéficos do suporte social recebido por mães, que apresentaram comportamentos mais adequados em relação a suas crianças. Em sua pesquisa, 44 mães foram entrevistadas sobre suas redes sociais, redigiram um diário de seus contatos com os membros da rede e foram observadas em interação com suas crianças de 04 anos de idade, em uma sessão de brincadeira. Os autores definiram dois tipos básicos de rede social das mães, a partir dos quais realizaram suas análises: (a) rede pessoal, que corresponde a todas as pessoas que a mãe considera importantes em sua vida, incluindo seu esposo, outros membros da família nuclear, parentes, amigos, vizinhos e outros e (b) rede maternal, que inclui as pessoas que a mãe considera importantes para o desempenho de seu papel de mãe, como aquelas com as quais ela conversa sobre a criança, que cuidam da mesma ou prestam outro tipo de assistência. Os resultados mostram que as mães que relataram níveis mais altos de satisfação com suas redes de apoio pessoais e tinham redes maternas mais extensas emitiram mais comportamentos maternais considerados adequados. Em outras palavras, essas mães eram menos intrusivas e controladoras e estabeleciam relações mais satisfatórias com suas crianças.

As pessoas que compõem a rede social de apoio e as funções que exercem mudam de acordo com o contexto sócio-cultural, o tempo histórico e o estágio de desenvolvimento do indivíduo e da família enquanto grupo. Um dos momentos em que se verificam alterações nesta rede social é quando a família passa por transições decorrentes do nascimento de filhos. Dessen (1997) verificou mudanças no sistema familiar logo após o nascimento do segundo filho, particularmente em relação à ampliação de pessoas e de funções da rede de apoio da família, que se caracterizou por uma maior participação dos parentes e do pai na vida familiar.

Com a chegada de um novo filho, são exigidas da família novas estratégias para lidar com as tarefas de desenvolvimento, capacidade de adaptação para receber o novo membro e habilidades para administrar as necessidades emergentes do sistema. Uma das tarefas dos genitores, nesse período, é buscar o equilíbrio do sistema familiar. Dessen (1997) afirma que:

A adaptação às exigências da nova situação depende, sobretudo, da complementaridade de papéis entre os genitores, não só em nível das interações como também das relações familiares mais amplas, incluindo a divisão de tarefas domésticas. A participação do pai como membro capaz de exercer o seu papel adequadamente, suprindo as deficiências naturais ocorridas no relacionamento da mãe com o primogênito, é fundamental para que o processo de adaptação seja bem sucedido. (p. 59)

As mães apontam o suporte do marido/companheiro como o principal dentre os apoios recebidos e, em segundo lugar, o de suas próprias mães. $\mathrm{O}$ apoio dos amigos e de outros membros familiares, como pai, sogro e sogra, é considerado como menos importante (Belsky, 1981; Bronfenbrenner, 1986; Levitt, Weber \& Clark, 1986). Alguns autores (Feiring \& Lewis, 1978; Kreppner, 1999; Minuchin, 1985, 1988; Sroufe \& Fleeson, 1988) revelam que casamentos saudáveis proporcionam mais suporte para os cônjuges, em especial do marido para a esposa, e que o apoio emocional oferecido pelos pais às mães contribui para o desenvolvimento dos filhos. O pai é, portanto, um dos membros mais importantes da rede social no que tange ao apoio oferecido à mãe $\mathrm{e}$ à família. Compreender os papéis desempenhados por ele, durante momentos de transição decorrentes do nascimento de filhos, é tarefa preponderante, se quisermos, de fato, com- 
preender a influência da rede social no funcionamento das famílias.

\section{Participação do pai e dos avós no contexto familiar}

Kreppner (1995) afirma que, em períodos de transição decorrentes do nascimento do segundo filho,

o pai tem que cumprir um conjunto de tarefas, dentre elas, estabelecer uma nova relação com o novo membro da família, ajudar a mãe no trabalho de cuidar de duas crianças e submeter-se ao seu novo papel de principal sócio do primeiro filho. Assim, a cooperação, ou a não cooperação, do pai durante este período constitui fator importante para o funcionamento da família. (p. 433)

A relevância da participação do pai para o desenvolvimento da criança, em geral, e para o equilíbrio da família é ressaltada por diversos autores (Dessen \& Lewis, 1998; Fthenakis \& Kalicki, 1999; Lewis, 2000; Lewis \& Dessen, 1999; Paquette, 1999; Phares, 1996; Phares \& Compas, 1992). O seu papel estende-se para além da realização de atividades como brincar e ficar com a criança. Vários são os fatores associados com a qualidade do investimento dos pais em relação aos filhos. Engle e Breaux (1998) apontam alguns deles: (a) viver numa cultura que valorize a igualdade entre gêneros e os cuidados dispensados pelo do pai aos filhos, (b) residir junto com sua esposa/companheira e sua criança, (c) ter uma relação harmoniosa com a mãe da criança que encoraje o seu envolvimento, (d) ser parte de um sistema econômico com recursos suficientes que lhe permita sustentar seu filho de acordo com as expectativas sociais e (e) trabalhar de forma cooperativa com sua esposa/ companheira para prover o sustento da família.

Apesar de o envolvimento dos pais com o trabalho restringir a sua oportunidade de participar mais freqüentemente de atividades relacionadas aos filhos, tanto pais quanto mães relatam a importância de dividir as tarefas domésticas entre os cônjuges (Fthenakis \& Kalicki, 1999). A literatura recente (Deppe, Fthenakis \& Minsel, 1999; Fthenakis \& Kalicki, 1999; Gillis, 2000; Lewis, 2000; Minsel, Fthenakis \& Deppe, 1999) traça um quadro bastante complexo para a compreensão do envolvimento paterno no cuidado de seus filhos e, conseqüentemente, do apoio fornecido pelos pais às mães.

A segunda fonte principal de apoio recebido pelas mães é o de suas próprias mães. Dados revelam que a autoridade da avó e o seu apoio têm uma importância particular para suas filhas mais do que para seus filhos (Lewis, 1987) e, em geral, as mães preferem a avó materna e parentes maternos como fonte de ajuda nos cuidados dispensados aos filhos (Ibañez-Novion, conforme citado por Ferreira, 1991). A ajuda dos avós no cuidado e desenvolvimento de seus netos e na execução de tarefas domésticas, bem como sua participação nas interações familiares, principalmente em momentos de transição, são ressaltadas por Houndoumadi (1996).

Em muitos países, os avós assumem não somente a responsabilidade de cuidar de seus netos, sendo um dos recursos utilizados pelas famílias em que pais e mães trabalham fora, como também auxiliam na educação das crianças, transmitindo experiências, valores e crenças acerca do desenvolvimento infantil. Os avós também são considerados fontes importantes de apoio para a família brasileira, especialmente para aquelas em que as mães possuem uma dupla jornada de trabalho (Brito-Dias, 1994; Ferreira, 1991).

Entretanto, conhece-se relativamente pouco a respeito da influência dos avós no desenvolvimento da criança (Tinsley \& Parke, 1988) e quase nada a respeito de sua participação em períodos de transição familiar decorrentes do nascimento de seus netos (Dessen, 1992). As pesquisas nessa área têm seguido o mesmo padrão dos estudos sobre a relação mãe-criança, ou seja, há um maior investimento em investigações sobre a influência das avós no desenvolvimento de seus netos do que sobre a relação avô-criança. Há uma série de questões que merecem ser estudadas no que diz respeito ao papel dos avós no desenvolvimento das crianças, para que se tenha uma compreensão mais completa do funcionamento do sistema familiar. Apesar disso, os pesquisadores (Biasoli-Alves, 1997; Simionato-Tozo \& Biasoli-Alves, 1998; Tinsley \& Parke, 1988) concordam com a importante influência que as diferentes gerações exercem umas sobre as outras, “...estabelecendo formas e limites para as relações e interações entre as gerações mais velhas e mais novas" (Simionato-Tozo \& Biasoli-Alves, 1998, p. 138).

Levando em consideração as modificações no contexto familiar durante transições decorrentes do nascimento de filhos, a necessidade da família encontrar um equilíbrio para lidar com as situações que surgem nesses períodos, a importância da rede social de apoio para sua adaptação às novas circunstâncias, particularmente a contribuição do pai e dos avós para o desenvolvimento, respectivamente, de seus filhos e netos, o presente estudo teve como principal objetivo investigar, a partir do ponto de vista de mães e de pais: (a) as transformações ocorridas na rede social de apoio de famílias brasilienses em períodos de transição familiar decorrentes do nascimento de filhos, (b) a participação do pai nesse contexto e (c) a participação e influência dos avós na vida familiar.

\section{Método}

\section{As famílias}

Participaram deste estudo 15 mães e 15 pais de famílias de classe social menos favorecida, residentes no Distrito Federal (87\% morando em cidades satélites e $13 \%$ no Plano Piloto). Das 15 mães, oito (53\%) estavam entre o $3^{\circ}$ e $8^{\circ}$ mês de gestação e sete (47\%) tinham tido bebês há menos de seis meses. A idade média das mães era de 21,9 anos e a dos pais de 20,9 anos. Dos trinta sujeitos, 20 (67\%), 10 mães e 10 pais, possuíam o $1^{\circ}$ grau incompleto, sendo $80 \%$ dos casais não legalmente casados, morando juntos por um período inferior a três anos.

Com relação ao número de filhos, $33 \%$ dos casais aguardavam a chegada do primeiro filho; $47 \%$ possuíam um fi- 
lho; os demais possuíam entre dois e quatro filhos. De um total de 16 filhos distribuídos em 10 famílias, 44\% tinham até seis meses de idade; $19 \%$ tinham entre um e quatro anos e $37 \%$ possuíam entre seis e 10 anos de idade. Todos os filhos, a maioria (67\%) do sexo feminino, moravam com suas respectivas famílias, exceto duas delas que tinham filhos morando com parentes e amigos.

Quanto à ocupação dos pais, $33 \%$ trabalhavam na construção civil, $13 \%$ em serviços operacionais, $13 \%$ no comércio/vendas e $13 \%$ seguiam a carreira militar, havendo, na época da coleta de dados, apenas um pai desempregado. Treze mães (87\%) eram donas-de-casa, uma professora e a outra operadora de caixa. A renda mensal de $33 \%$ das famílias variava entre $\mathrm{R} \$ 241,00$ (pouco mais de um salário mínimo) e $\mathrm{R} \$ 360,00$.

\section{Procedimento}

Primeiramente, foram contatados os centros de saúde da Fundação Hospitalar do Distrito Federal com os objetivos de apresentar o projeto de pesquisa e solicitar a colaboração e a permissão de seus profissionais para realizar o estudo. Em seguida, foram consultados os fichários dos setores de ginecologia e pediatria dos referidos centros, tendo sido selecionadas famílias de dois grupos. No Grupo A, as mães, primíparas ou não, estavam entre o $3^{\circ}$ e o $9^{\circ}$ mês de gestação diagnosticada como normal; no Grupo B, as mães haviam tido bebês há, no máximo, seis meses.

As mães eram, então, contatadas nos respectivos setores, pediatria ou ginecologia, e informadas sobre os objetivos da pesquisa. Sua colaboração era solicitada e, havendo concordância, ela assinava um termo de consentimento e respondia um questionário que era lido pelo próprio pesquisador, que se encarregava também de anotar as respostas no protocolo. Este procedimento foi necessário, para evitar constrangimentos decorrentes de possíveis dificuldades de leitura por parte das mães.

O questionário era composto por três partes: (a) características demográficas da família (estado civil, idade, escolaridade etc.), (b) caracterização do sistema familiar (contato social da família, divisão de trabalho doméstico etc.) e (c) características da rede social de apoio durante períodos de transição decorrentes do nascimento de filhos (pessoas da rede, tipo de apoio recebido etc.). Imediatamente após o término do questionário, as mães participavam de uma entrevista semi-estruturada gravada em áudio. $\mathrm{O}$ roteiro investigava os seguintes aspectos: (a) alterações da rede de apoio durante a gravidez e após o nascimento do bebê, (b) participação e apoio dispensados pelo marido/companheiro em relação às tarefas rotineiras da casa e aos cuidados com os filhos, (c) sentimentos e expectativas quanto à participação do pai na vida familiar e (d) influência dos avós na vida familiar.

Quando o pai se encontrava presente, acompanhando a mãe, a sua colaboração para participar da pesquisa era solicitada. Havendo concordância, o termo de consentimento era assinado por ele e o mesmo roteiro de entrevista semi- estruturado era aplicado. Quando os pais não estavam presentes, a pesquisadora obtinha o consentimento e realizava a entrevista na casa da família.

\section{Resultados}

Os resultados são descritos focalizando a estrutura e o contato social da família, a divisão do trabalho doméstico e a responsabilidade pelo cuidado dos filhos, a participação e o envolvimento do pai na vida familiar. Além disso, descreve-se, ainda, o apoio recebido e as mudanças percebidas na rede social durante períodos de transição decorrentes do nascimento dos filhos, as expectativas quanto à participação do pai na vida familiar e a participação e influência dos avós na vida da família e no desenvolvimento da criança.

\section{Estrutura e contato social da família}

A maioria das famílias $(67 \%)$ possuía parentes morando na mesma casa ou no mesmo lote ${ }^{3}$, sendo $56 \%$ e $44 \%$ parentes da mãe e do pai, respectivamente. Dentre eles, destacam-se os avós (48\%) e tios (41\%) maternos e paternos da criança recém-nascida ou que iria nascer e outros parentes $(11 \%)$ como padrasto, primos e sobrinhos da mãe ou pai.

As atividades de lazer das famílias eram diversificadas: passeios ao zoológico, parques e clubes (47\%); idas ao shopping e/ou cinema (13\%) e a chácaras ou fazendas (7\%); visitas a parentes e amigos (27\%). Assistir à TV e/ou ouvir música $(27 \%)$, praticar esportes $(7 \%)$ e conversar com amigos/vizinhos na rua $(7 \%)$ também foram relatadas. A maioria das mães $(53 \%)$ relatou que sua família participava dessas atividades de lazer pelo menos uma vez por mês, tendo, em geral, a companhia do marido e dos filhos (67\%) e/ou de parentes $(40 \%)$ e amigos/vizinhos (27\%). Estas atividades eram realizadas mais freqüentemente nos finais de semana. Durante a semana, as famílias $(60 \%)$ ficavam em casa e "não faziam nada em especial".

\section{Trabalho doméstico e cuidado dos filhos: tarefas compartilhadas}

As mães eram as principais responsáveis pela realização das tarefas domésticas e pelos cuidados dispensados aos filhos. Os pais, os avós, os irmãos da criança e outras pessoas também colaboravam, executando algumas das atividades domésticas, conforme relatado pelas 15 mães (ver Tabela 1).

As mães com filhos recém-nascidos (Grupo B) relataram um percentual maior de pessoas envolvidas nas tarefas de cuidados dos filhos do que as mães grávidas (Grupo A) que também tinham filhos. No Grupo B, $40 \%$ das mães, $27 \%$ dos pais e $20 \%$ dos avós cuidavam dos filhos, enquan-

3 Em um mesmo lote, pode haver mais de um barraco. Nesse caso, as famílias e seus parentes compartilham o quintal ou a área livre do lote. 
Tabela 1. Participação de Membros Familiares e de Outras Pessoas na Execução de Atividades Domésticas

\begin{tabular}{|c|c|c|c|c|c|c|c|c|c|c|}
\hline \multirow{2}{*}{ Atribuições } & \multicolumn{2}{|c|}{ M ãe } & \multicolumn{2}{|c|}{ Pai } & \multicolumn{2}{|c|}{ Irmão } & \multicolumn{2}{|c|}{ Avós } & \multicolumn{2}{|c|}{ O utros* } \\
\hline & Fr. & $\%$ & Fr. & $\%$ & Fr. & $\%$ & Fr. & $\%$ & Fr. & $\%$ \\
\hline Cuidado dos filhos & 08 & 80 & 06 & 60 & - & - & 05 & 50 & - & - \\
\hline Dar comida/banho & 09 & 90 & 03 & 30 & 01 & 10 & 03 & 30 & - & - \\
\hline Levar para escola & 01 & 10 & - & - & - & - & 01 & 10 & - & - \\
\hline Orientar dever & 02 & 20 & - & - & 01 & 10 & - & - & - & - \\
\hline Levar para lazer & 02 & 20 & 01 & 10 & 01 & 10 & - & - & 01 & 10 \\
\hline Colocar para dormir & 02 & 20 & 01 & 10 & - & - & - & - & - & - \\
\hline A rrumar a casa & 13 & 86,6 & 07 & 46,6 & 01 & 6,6 & 03 & 20 & 03 & 20 \\
\hline Cozinhar & 13 & 86,6 & 02 & 13,3 & 01 & 6,6 & 03 & 20 & - & - \\
\hline Lavar/Passar & 13 & 86,6 & 03 & 20 & 02 & 13,3 & 02 & 13,3 & 01 & 6,6 \\
\hline Fazer compras & 14 & 93,3 & 12 & 80 & - & - & 01 & 6,6 & - & - \\
\hline Orientar empregada & 01 & 6,6 & - & - & - & - & - & - & - & - \\
\hline
\end{tabular}

Nota. Considerando que algumas atribuições são próprias de famílias com filhos, o número de respondentes variou: $n=10$ para as seis primeiras categorias e $N=15$ para as restantes. A categoria "Outros" inclui primos do pai ou da mãe, empregada doméstica e vizinhos.

to no Grupo A esse percentual era de apenas $13 \%$, para cada um dos membros citados. Quanto à arrumação da casa, as mães do Grupo A relataram maior envolvimento delas próprias $(95 \%)$ e dos pais $(29 \%)$ comparadas às do Grupo B $($ mães $=76 \%$; pais $=17 \%)$. Quando o pai e/ou a mãe estão trabalhando, a responsabilidade pelo cuidado dos filhos é das mães, dos pais, dos avós ou empregada doméstica ou, então, eles ficam sozinhos (ver Tabela 2).

\section{Participação e envolvimento do pai na vida familiar: um relato de mães e pais}

Tanto os pais como as mães falaram sobre a participação e o apoio do pai em tarefas domésticas e nos cuidados dispensados aos filhos. A maioria das mães (80\%) relatou que os pais realizavam algum trabalho doméstico (por exemplo: "Ajuda a arrumar a casa, ele (pai) lava louça, ele é igual a uma dona de casa.") e se referia a eles como "muito bonzinho". Já os pais disseram que ajudavam em casa naquilo que podiam e quando possível, isto é, após chegarem do trabalho ou nos finais de semana. Por exemplo, "Eu faço é tudo! É só eu tá em casa. Banho ela (criança), troco ela, faço comida, lavo louça, limpo casa, limpo tudo aqui dentro. Faço tudo que está ao meu alcance." "Quando eu estou de folga, eu faço comida, limpo a casa, a única coisa que eu não faço é lavar roupa. Mas, matéria de fazer almoço e limpar a casa, quando eu posso fazer, quando eu estou em casa, eu faço."

No entanto, houve diferenças nos relatos das mães dos Grupos A e B. Apenas as mães do Grupo A relataram que

Tabela 2. Responsabilidade pelo Cuidado dos Filhos, Segundo as Mães que têm Filhos $(n=10)$

\begin{tabular}{lcc}
\hline Responsável & Fr. & $\%$ \\
\hline M ãe & 07 & 70 \\
Pai & 02 & 20 \\
Babá/Empregada doméstica & 01 & 10 \\
Avós & 02 & 20 \\
Ficam sós & 01 & 10 \\
\hline
\end{tabular}

os pais cozinhavam, lavavam roupas e executavam serviços mais pesados. Já os pais dos Grupos A e B mencionaram executar tarefas similares: passar/lavar roupa, lavar louça, cozinhar, arrumar/limpar a casa. Se os casais têm filhos (n = 10), os pais dão comida, banho, trocam fraldas/roupas, brincam e levam os filhos para atividades de lazer. Mas, de acordo com os pais $(80 \%)$ e as mães $(60 \%)$, em especial as do Grupo B (40\%), a tarefa na qual os pais mais se engajam é "tomar conta dos filhos", isto é, ficar com eles, segurálos ou vigiá-los.

\section{Apoio recebido e mudanças decorrentes do período de transição familiar}

A maioria das mães relatou a ocorrência de mudanças na sua rede de apoio durante a sua gravidez atual $(80 \%)$ e última gravidez $(60 \%)$, que foram tanto positivas $(70 \%)$, quanto negativas (30\%). Dentre as alterações positivas foram citadas: apoio psicológico ${ }^{4}(70 \%)$; cuidados físicos e orientações recebidas sobre alimentação, gravidez e filhos $(60 \%)$; ajuda financeira $(20 \%)$; ajuda nas tarefas domésticas e cuidado dos filhos (13\%); melhoria no relacionamento com o marido e a família (13\%). As negativas foram: não receber o apoio psicológico esperado (27\%); afastamento de amigos/outras pessoas (20\%); dificuldades no relacionamento com o marido e a família (20\%); alterações de humor (nervosismo, agressividade) (13\%); parar de trabalhar (13\%); mudanças nas atividades de lazer (7\%).

Para os pais, as mudanças positivas nesse período foram relacionadas ao apoio psicológico recebido pela família (67\%), como a aprovação dos parentes, atenção e conversas, e, também, à ajuda financeira recebida dos parentes (93\%). Como alteração negativa, alguns pais (33\%) mencionaram não ter recebido o apoio psicológico necessário. Houve concordância no relato dos pais e das mães quanto

4 O apoio psicológico refere-se à simples presença de familiares e amigos ou ao seu apoio expresso por carinho, dedicação e atenção. 


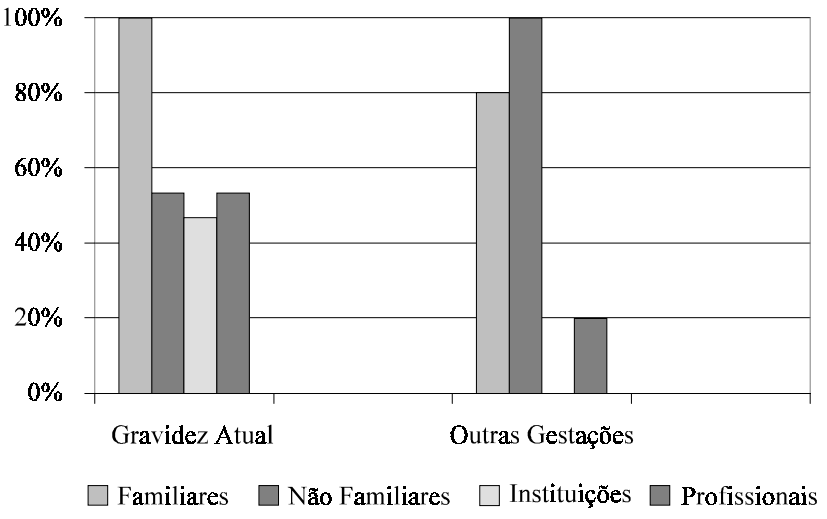

Figura 1. Fontes de apoio das famílias durante transições decorrentes do nascimento de filhos, segundo o relato de mães.

ao recebimento de apoio psicológico; no entanto, apenas as mães mencionaram as categorias de afastamento de amigos/outras pessoas e alterações de humor.

Quanto à fonte de apoio durante a última e a gravidez atual, as mães destacaram os suportes de familiares, não familiares, instituições e profissionais (ver Figura 1). Dentre os familiares que mais apoiaram as mães, destacam-se o marido/companheiro, os avós maternos e paternos e os tios maternos e paternos. $\mathrm{O}$ apoio recebido do marido/companheiro foi considerado, por $60 \%$ das mães, o mais importante, seguido pelo apoio das avós maternas. A Tabela 3 mostra as pessoas apoiadoras das mães na gravidez atual e em gestações anteriores.

Sobre o contato social, tanto as mães quanto os pais responderam que houve uma diminuição de atividades de

Tabela 3. Fontes de Apoio à Mãe Durante Transições Decorrentes do Nascimento de Filhos

\begin{tabular}{ccccc}
\hline Fontes de A poio & \multicolumn{2}{c}{$\begin{array}{c}\text { G ravidez Atual } \\
\text { (N = 15) }\end{array}$} & $\begin{array}{c}\text { O utras G estações } \\
\text { (n = 5) }\end{array}$ \\
\hline Familiares & Freq. & $\%$ & Freq. & $\%$ \\
M arido/Parceiro & 15 & 100 & 04 & 80 \\
Avós: M aternos & 15 & 100 & 03 & 60 \\
Paternos & 10 & 66,6 & 05 & 100 \\
Tios: M aternos & 09 & 60 & 02 & 40 \\
$\quad 11$ & 73,3 & 01 & 20 \\
Paternos & 02 & 13,3 & 01 & 20 \\
Outros & 02 & 13,3 & - & - \\
\hline Não Familiares & 08 & 53,3 & 05 & 100 \\
A migos & 04 & 26,6 & 04 & 80 \\
Vizinhos & 02 & 13,3 & - & - \\
Empregada/babá & 01 & 6,6 & 01 & 20 \\
Outros & 01 & 6,6 & 01 & 20 \\
\hline Instituições & 07 & 46,6 & - & - \\
Centro de Saúde & 05 & 33,3 & - & - \\
Outros & 02 & 13,3 & - & - \\
\hline Profissionais & 08 & 53,3 & 01 & 20 \\
M édico & 07 & 46,6 & 01 & 20 \\
Outros & 01 & 6,6 & - & - \\
\hline
\end{tabular}

Nota. As mães relataram mais de uma fonte de apoio. lazer e um aumento no tempo de permanência em casa, nos períodos de transição. Por exemplo, as mães relataram: "O tempo agora é só para os filhos." "Eu já não tinha muitos amigos, sabe! Aí, eu fiquei grávida, aí, piorou tudo, eu fiquei só mesmo." "Antes de ficar grávida, eu ia de casa para a igreja e da igreja para casa. Agora, nem na igreja eu não vou mais." Para os pais, "a pessoa se afasta da maioria dos amigos que são solteiros, a pessoa procura mais amizade com as pessoas que já tem família."

Em relação à divisão de tarefas domésticas, as mães $(53,3 \%)$ disseram que passaram a receber mais ajuda do marido, de irmãos, da avó paterna, de vizinhos e de outras pessoas durante a gravidez ou logo após o nascimento do bebê. O exemplo, a seguir, ilustra bem este tipo de ajuda: "Nos dias que eu não posso fazer e que não tem ninguém lá para fazer, eu não faço. Meu marido já falou: - 'Não precisa se preocupar comigo, fazer comida, essas coisas...' Aí, eu não faço quando estou mal, quando eu sinto enjôo. E, quando eu estou enjoada, sempre aparece alguém para fazer para mim." Os pais $(60 \%)$ também relataram alterações na execução das tarefas domésticas e no cuidado dos filhos, destacando o aumento de sua participação nessas atividades. Exemplos: "Quando eu chego, eu gomo as fraldas do neném. Quando eu tô em casa, eu procuro sempre estar tentando ajudar para ela (mãe) não pegar peso, não se abaixar." "Eu tinha pena dela (mãe) porque ela ficava bem fraca; eu fazia o possível." "Quando ela (mãe) tá passando mal, aí é minha mãe ou eu quem faz."

\section{Expectativas quanto à participação do pai na vida familiar: o pai real e o pai ideal na visão de mães e pais}

O pai faz o que deveria fazer em casa ou ele deveria fazer mais alguma coisa? Se sim, o quê? À esta questão, $87 \%$ das mães (todas as do Grupo A e 57\% das do Grupo B) responderam positivamente, isto é, elas acham que os seus companheiros fazem o que deveriam fazer em casa e estão satisfeitas com eles neste aspecto. Exemplos: "Ele trabalha, chega e ainda ajuda. Acho que ele faz até demais." "Ele faz até mais que ele poderia, porque, às vezes, é coisa que mulher tem que fazer e ele faz, ele faz comida, ele faz, quando dá na veneta, ele faz. Ele me ajuda bastante." "É um marido que qualquer uma mulher pede para Deus, porque o da minha irmã não sabe fazer nada dentro de casa." Apenas três mães relataram que seus companheiros deveriam participar mais das atividades de casa, da escola e do cuidado dos filhos, além de passar mais tempo em casa com a família. Exemplo: "Ele podia me ajudar mais com a criança, porque fica muito apertado, igual, eu tô lavando roupa e ela tá chorando pra mamar, ele devia pegar ela, brincar com ela ou qualquer coisa e ele não está em casa. Ele tá jogando dominó, ele tá na rua com os amigos dele."

Por outro lado, a maioria dos pais (53\%) acha que não faz o que deveria fazer em casa e que deveria fazer algo mais. Exemplo: "O que eu devia fazer, eu devia fazer, mas só que o tempo também é escasso." "Porque a gente não quer só a mulher para fazer só o que a gente quer, a gente 
tem que ajudar ela. Ela me ajuda e eu ajudo ela." Os pais $(67 \%)$ acham que poderiam/deveriam ajudar mais nas tarefas domésticas, no cuidado dos filhos, ficar mais tempo em casa com a família, ter um emprego fixo para auxiliar financeiramente e estudar. Exemplos: "Arrumar a casa... Mas só que eu não gosto, mas acho que eu poderia fazer isso, chegar e arrumar a casa, mas eu não faço. Pegar uma roupa para lavar sozinho, mas só que eu não gosto. Mas eu poderia, né?" "Ficar menos tempo na rua e não chegar muito tarde em casa."

Quando solicitadas a falar sobre o que seria uma participação ideal do pai na vida familiar, as mães responderam que uma participação "ideal" do pai implicaria em: (a) oferecer atenção, carinho, apoio e compreensão às mães (33\%) e aos filhos (13\%); (b) cuidar dos filhos (13\%); (c) não bater, não "implicar" com a mãe e não beber (13\%); (d) ficar em casa com a família, não saindo só ou chegando tarde (33\%). Exemplos: "Primeiramente, carinho com os filhos; segundo, atenção e, quando precisar, ir ao médico, levar também, que não é só a mãe que é obrigada, só isso."

Os pais responderam que seu papel "ideal" na vida familiar seria: (a) oferecer atenção, carinho, apoio e compreensão às mães e à família (53\%) e (b) oferecer atenção, carinho, cuidados e impor regras e correção aos filhos (87\%). Exemplos: "Tá perto da mulher, conversando, sabendo como foi o dia-a-dia, isso é que acho que seria o pai ideal." "O pai ideal é aquele que dá carinho, dá assistência para a criança, tá sempre ali na hora que ele precisa mais. Basicamente essa parte." "É aquele que deveria ter tempo para estar com os filhos, lazer, brincando, orientando como se comportar em casa, porque de casa é que você leva a educação para rua. A educação vem dos pais. Procurando saber o que o filho tem, como é que o filho passou o dia, participando da alimentação do filho, participando do nascimento do bebê, tanto no hospital, quanto nas brincadeiras do filho. Esse é o pai ideal." Alguns pais também relataram que: (a) auxiliar nas tarefas domésticas (7\%) e assumir a responsabilidade pelo sustento da família (20\%) fazem parte do papel ideal do pai. Exemplo: "O pai tem que saber suportar tudo isso, essa barra não é fácil. Então, a gente tem que saber tocar a bola para frente, tem que sabê se virar, tem que trabalhar muito, principalmente, tendo responsabilidade em casa, com filho e tudo."

Em síntese, para os pais, o aspecto principal de sua participação "ideal" no contexto familiar é dar atenção e carinho, dispensando os cuidados necessários e impondo regras aos filhos; em segundo lugar, o apoio psicológico às mães e à família como um todo. Em outras palavras, os pais consideram fundamental seu papel na educação e na criação dos filhos e na relação com a companheira, enquanto as mães esperam deles apoio psicológico e companhia em casa.

\section{Participação e influência dos avós na vida familiar}

Tanto os pais quanto as mães (57\%) consideram os avós importantes para a família, quer porque prestam apoio psi- cológico ou se preocupam com a família, quer porque ajudam nas necessidades materiais e financeiras ou contribuem com a experiência de vida para resolver situações difíceis. Mas, houve diferença nos relatos dos pais dos Grupos A e B. Os pais do Grupo A (75\%) consideraram primordial o apoio psicológico recebido dos avós, concordando com a maioria das mães de ambos os Grupos. Já para os pais do Grupo B, a ajuda material/financeira oferecida pelos avós $(57, \%)$ foi considerada mais importante que o apoio psicológico $(43 \%)$.

Embora 53\% dos entrevistados tenham relatado que os avós não interferem ou atrapalham a vida familiar, houve diferenças entre os pais e as mães e entre os Grupos. A maioria das mães $(67 \%)$ concordou com a afirmação acima, enquanto os pais (53\%) discordaram. No entanto, ambos concordam que a influência dos avós na vida familiar ocorre, principalmente, na esfera de educação e criação dos filhos. Exemplo: "Porque meu pai criou a gente de uma maneira rígida, mas boa. Porque todos nós aprendemos muito com isso. A gente nunca foi prejudicado pelo fato de meu pai chegar e dar um conselho forte. Ele sempre teve razão, meu pai e minha mãe, quando chegava e falava alguma coisa assim para a gente."

Quanto aos padrões, às condutas e às regras transmitidas pelos avós que exercem influência no modo de vida familiar, $47 \%$ das mães e $73 \%$ dos pais responderam que os avós orientam na rotina da casa e na educação e criação dos filhos, transmitindo informações e regras. Exemplos desses dados estão presentes nas seguintes falas: "Já minha mãe foi essa mãe e esse pai que tive. Ensinou eu passar, lavar louça, fazer comida, me comunicar, saber conversar para não me decepcionar... Essa educação que meu pai me passou que eu tento passar para eles (filhos), que é andar limpinho, não andar xingando, saber respeitar os mais velhos, toda pessoa de idade para eles já é um avô ou uma vovó. Não entrar nas casas alheias e o que vê não pegar... Quando eles estão brincando com outro menino a gente tem sempre que estar de olho, porque foi assim que minha mãe me ensinou, que menino ninguém deve dar um pouquinho de liberdade se não faz uma marmota, né?"

Sobre a participação e a influência dos avós durante os períodos de transição da família decorrentes do nascimento de filhos foram destacados o apoio, o auxílio material e os cuidados prestados à mãe/família durante a hospitalização da mãe e após o nascimento do bebê. Para os pais e mães do Grupo A (30\%), os avós apoiam dando conselhos e orientações sobre o cuidado dos filhos, gravidez, alimentação e transmitindo suas experiências passadas. Exemplos: "Ela (avó materna) tá sempre querendo saber como eu tô, a respeito do meu bem-estar, sobre eu me adaptar..."

\section{Discussão}

As alterações na rede social de apoio de famílias pobres durante períodos de transição decorrentes do nascimento de filhos caracterizaram-se, principalmente, pelo aumento nos suportes emocional e instrumental recebidos de famili- 
ares e não familiares. Durante este tipo de transição no desenvolvimento da família, o auxílio é recebido, principalmente, da família materna e de parentes do sexo feminino (Brito-Dias, 1994; Ferreira, 1991; Lewis, 1987), o que foi corroborado pelos dados desse estudo. Dentre os familiares, o marido/companheiro foi apontado como a principal fonte de apoio e, em segundo lugar, as avós maternas, conforme relatado na literatura (Belsky, 1981; Bronfrenbrenner, 1986; Levitt, Weber \& Clark, 1986).

$\mathrm{O}$ apoio psicológico recebido, tanto de familiares como de não familiares, foi considerado fundamental para o bem estar da família durante este período, segundo o relato das mães; no entanto, para os pais, a ajuda financeira e material recebida foi relatada como sendo de maior relevância. Estes dados mostram que pais e mães têm valores diferentes, possivelmente associados aos papéis de gênero feminino e masculino. Embora haja uma forte tendência à mudança de valores no que tange aos papéis atribuídos aos pais nos tempos modernos (Deutsch, Lussier \& Servis, 1993; Lewis, 2000; Lewis \& Dessen, 1999), os relatos dos pais e das mães desse estudo indicam que as mulheres continuam valorizando o seu papel de "guardiã" da situação afetiva e psicológica da família, enquanto a figura do pai continua associada ao papel de "provedor".

Nessas famílias, a maioria das mulheres não trabalhava fora de casa, sendo atribuído ao homem a responsabilidade por prover e sustentar a família e, à mulher, a responsabilidade pelos cuidados e educação dos filhos, manutenção da limpeza e organização da casa. Tais dados são similares aos encontrados por outros pesquisadores (Lewis, 1987; Ribeiro, Sabóia, Branco \& Bregman, 1998; Tudge, Hayes, Doucet, Odero, Kulakova, Tammeveski, Meltsas \& Lee, 2000). A justificativa principal apresentada pelos pais para a sua menor participação na rotina da casa foi a falta de tempo em virtude de trabalharem o dia todo e estarem em casa apenas à noite e nos finais de semana. Dados semelhantes foram encontrados por Tudge e cols. (2000), independentemente de momentos de transição decorrentes do nascimento de filhos. Em sua pesquisa, os pais gastavam menos horas em atividades com suas crianças do que as mães e, na maioria das vezes, isto se devia ao fato de eles estarem trabalhando, o que reduzia a sua possibilidade de participação na rotina doméstica.

Com relação ao "ideal" de participação do pai na vida da família, a maioria das mães considerou a atenção, o carinho, o apoio e a compreensão dispensados a elas, bem como a presença física do pai em casa como aspectos essenciais ao bem-estar da família e dos filhos, em geral. Há muitas evidências na literatura de que a qualidade da relação conjugal exerce uma forte influência nas atitudes parentais (Deppe, Fthenakis \& Minsel, 1999; Erel \& Burman (1995); Feiring \& Lewis, 1978; Fthenakis \& Kalicki, 1999; Heavey, Shenk \& Christensen, 1994; Kreppner, 1999; Minsel, Fthenakis \& Deppe, 1999; Minuchin, 1985, 1988; Sroufe \& Fleeson, 1988).

Para os pais, o mais importante era o seu papel na educação e na criação dos filhos e sua contribuição mais ampla na relação com a companheira e na família, o que denota uma visão coerente com o modelo de pai "moderno" (Dessen \& Lewis, 1998). Neste modelo, o pai se preocupa com a educação dos filhos, principalmente nas áreas de desenvolvimento moral, tipificação sexual e competência escolar, mas não compartilha igualmente com a esposa/companheira as atividades domésticas, como no modelo de pai emergente. Os nossos dados sugerem que o fato de as mães não trabalharem fora de casa contribui muito mais para a manutenção do modelo de pai moderno que o fator econômico propriamente dito. No entanto, tal suposição precisa ser melhor investigada em pesquisas futuras.

Apesar do pouco engajamento do pai na vida familiar, as mães se mostram muito mais satisfeitas com seus maridos/companheiros que eles mesmos, em se tratando do seu desempenho no trabalho doméstico e no cuidado dos filhos. Os pais acham que poderiam e deveriam fazer mais do que realmente fazem em casa. Os dados sugerem que as mães podem estar, na prática, dificultando o engajamento dos pais na rotina da família, por considerarem esta função atribuição exclusiva das mães, já que elas não trabalham fora de casa e/ou por acreditarem que tais tarefas domésticas são exclusivamente femininas. Pesquisas que focalizem a percepção, as crenças, os valores e as expectativas de pais e mães sobre os seus papéis e engajamentos na vida familiar precisam ser estimuladas para que possamos compreender melhor a dinâmica das relações maritais e parentais.

Durante as transições decorrentes do nascimento de filhos, os pais parecem se ajustar às condições de gravidez da mãe. Apenas os pais do Grupo A executaram as tarefas de cozinhar, lavar roupas e outros serviços mais pesados, que exigiam maior esforço físico. Novamente, estes dados podem estar associados às crenças populares de que a mulher grávida não pode fazer serviço pesado, pois isso poderia acarretar problemas a ela e ao bebê. Quando o bebê nasce (Grupo B), essa preocupação desaparece e os pais deixam de auxiliar as mães nas tarefas domésticas e na execução de serviços pesados. Por outro lado, tais resultados podem estar associados ao tipo de divisão de trabalho doméstico estabelecido nesses períodos de transição, cujas tarefas aumentam em decorrência da presença de um bebê na família, conforme descrito por Kreppner (1988), Kreppner e cols. (1982) e Dessen (1997). Após o nascimento do bebê, os pais passam a cuidar mais dos filhos, principalmente dos mais velhos, no tempo em que permanecem em casa, permitindo às mães que descansem do trabalho de cuidar das crianças, enquanto se dedicam a executar outras tarefas domésticas como lavar, passar e cozinhar. Esta questão parece estar mais relacionada a "estratégias de sobrevivência" do que aos papéis de gênero e merece ser investigada em estudos futuros.

$\mathrm{O}$ fato de as mães do Grupo B terem relatado menos satisfação em relação ao apoio recebido de seus maridos/ companheiros que as do Grupo A, enquanto os pais do Grupo $\mathrm{B}$, por sua vez, relataram que deveriam participar mais da vida familiar que os do Grupo A sugere que a sobrecarga de trabalho decorrente dos cuidados dispensados ao bebê 
requer da família uma readaptação às demandas da nova situação. Além disto, as variações no comportamento do bebê, devido ao seu desenvolvimento, também exigem adaptações constantes por parte de toda a família. Segundo Kreppner (1991) e Dessen (1997), a adaptação da família em períodos de transição decorrentes do nascimento de filhos depende não somente de a família ser capaz de realizar as tarefas concretas de cuidado e sustento do novo membro familiar, como também de superar adequadamente as tarefas de desenvolvimento requeridas pela nova estrutura e funcionamento dessa família.

Neste processo de adaptação, os avós desempenham papel preponderante, principalmente através de sua influência indireta na família que se forma. Os pais e mães de nosso estudo valorizam a educação que receberam de seus genitores e tentam transmiti-las aos seus filhos. Mais que as mães, os pais mencionaram a transmissão de informações, as orientações recebidas e os conselhos sobre a educação e a criação dos filhos por parte dos avós como exercendo influência positiva no modo de vida familiar, embora a maioria das mães tenha relatado que os avós não atrapalham a vida da família. Os dados sugerem que pais e mães tem percepções diferentes sobre o envolvimento dos avós na rotina das famílias, talvez em decorrência do pouco envolvimento dos pais na vida familiar.

Quanto ao tipo de apoio dos avós, verificou-se que o apoio psicológico dos mesmos é considerado importante tanto para pais quanto para mães. No entanto, para os pais do Grupo B, a ajuda material e financeira oferecida pelos avós foi considerada mais importante que o apoio psicológico. Este dado pode ser compreendido em função da situação financeira precária da maioria das famílias e da divisão tradicional dos papéis de gênero. A chegada de um novo membro à família intensifica os gastos e onera ainda mais o orçamento da família que já é escasso. Além disso, os pais, como já foi mencionado anteriormente, estão mais preocupados com o suporte material e financeiro por desempenharem o papel tradicional de "provedores" da família. Os dados de nosso estudo sugerem que o apoio prestado pelos avós e as estratégias de auxílio empregadas por eles são apropriadas à demanda e à situação particular vivenciada pela família nos momentos de transição. Investigações sobre a influência e a participação dos avós na educação de seus netos e no apoio fornecido à famílias em diferentes contextos sociais e culturais têm sido muito enfatizadas recentemente (Biasoli-Alves, 1997; Brito-Dias, 1994; Ferreira, 1991; Houndoumadi, 1996; Lewis, 1987; Simionato-Tozo \& Biasoli-Alves, 1998; Tinsley \& Parke, 1988; Voss, 1991). Tais pesquisas possibilitarão uma compreensão mais efetiva do funcionamento das famílias durante os momentos de transição.

Em síntese, durante transições normativas decorrentes do nascimento de filhos ocorrem transformações na família que exigem uma reestruturação e adaptação de seus membros às novas demandas. Uma readaptação bem sucedida requer mudanças não somente no papel do pai como também na rede social de apoio das famílias. A literatura sobre o papel do pai no desenvolvimento da criança ainda é bastante controversa. As pesquisas sobre o tema não têm dispensado a atenção necessária ao pai e as informações sobre eles, em geral, são obtidas pelo relato das mães (Lewis \& Dessen, 1999). Com relação ao papel dos avós, há consenso entre os pesquisadores quanto ao conhecimento relativamente escasso a respeito da sua influência no desenvolvimento da criança e na vida familiar (Tinsley \& Parke, 1988). As lacunas acerca do impacto intergeracional na vida dos indivíduos e do sistema familiar precisam ser preenchidas na literatura.

Finalmente, é preciso ressaltar que há pouca dúvida quanto à importância do suporte social para a saúde física e emocional do indivíduo e, conseqüentemente, da família (Rhodes \& Lakey, 1999). As pesquisas sobre a rede social de apoio, que constitui objeto de estudo de várias disciplinas como a Medicina, a Sociologia e a Psicologia, precisam considerar, em seus planejamentos, a diversidade e a complexidade da rede social e dos apoios recebidos e percebidos pelos membros da família. O avanço nessa área permitirá uma compreensão mais aprofundada das relações maritais e parentais e dos períodos de transição normativos decorrentes do nascimento de filhos.

\section{Referências}

Basic Behavioral Science Task Force of the National Advisory Mental Health Council (1996). Basic behavioral science research for mental health: Family processes and social networks. American Psychologist, 51, 622-630.

Belsky, J. (1981). Early human experience: A family perspective. Developmental Psychology, 17, 3-23.

Biasoli-Alves, Z.M.M. (1997). Famílias brasileiras do século XX: os valores e as práticas da educação da criança. Temas em Psicologia, 3, 33-49.

Brito-Dias, C.M.S. (1994). A importância dos avós no contexto familiar. Psicologia: Teoria e Pesquisa, 10, 31-40.

Bronfenbrenner, U. (1986). Ecology of the family as a context for human development: Research perspectives. Developmental Psychology, 22, 723-742.

Bronfenbrenner, U. (1996). Ecological systems theory. Em R. Vasta (Org.), Six theories of child development (pp. 187-249). Londres: Jessica Kingsley Publishers.

Craig, St.J. \& Winston, T.J. (1989). The effect of social support on prenatal care. Journal of Applied Behavioral Science, 25, 79-98.

Crittenden, P.M. (1985). Social networks, quality of child rearing, and child development. Child Development, 56, 12991313.

Deppe, U., Fthenakis, W.E. \& Minsel, B. (1999, setembro). The paternal role in the context of personal orientations. Trabalho apresentado em IXth European Conference on Development Psychology, Atenas, Grécia.

Dessen, M.A. (1992). Efeitos do nascimento de uma segunda criança no comportamento e nas relações entre o primogênito e genitores. Tese de Doutorado, Universidade de São Paulo, São Paulo. 
Dessen, M.A. (1994). Interações e relações no contexto familiar: questões teóricas e metodológicas. Psicologia: Teoria e Pesquisa, 10, 213-220.

Dessen, M.A. (1997). Desenvolvimento familiar: transição de um sistema triádico para poliádico. Temas em Psicologia, 3, 5161.

Dessen, M.A. \& Lewis, C. (1998). Como estudar a família e o pai. Cadernos de Psicologia e Educação Paidéia, 8, 105-122.

Deutsch, F.M., Lussier, J.B. \& Servis, L.J. (1993). Husbands at home: Predictors of paternal participation in childcare and housework. Journal of Personality and Social Psychology, 65, 1154-1166.

Engle, P.L. \& Breaux, C. (1998). Fathers' involvement with children: Perspectives from developing countries. Social Policy Report: Society for Research in Child Development, XII(1), 1-23.

Erel, O. \& Burman, B. (1995). Interrelatedness of marital relations and parent-child relations: A meta-analytic review. Psychological Bulletin, 118, 108-132.

Feiring, C. \& Lewis, M. (1978). The child as a member of the family system. Behavioral Science, 23, 225-233.

Ferreira, E.A.P. (1991). Irmãos que cuidam de irmãos na ausência dos pais: um estudo sobre desempenho de tarefas domésticas e interação entre irmãos. Tese de Mestrado, Universidade de Brasília, Brasília.

Fthenakis, W.E. \& Kalicki, B. (1999, setembro). Subjective conceptions of fatherhood: An expanded approach. Trabalho apresentado em IXth European Conference on Development Psychology, Atenas, Grécia.

Gillis, J.R. (2000). Marginalization of fatherhood in western countries. Childhood: A Global Journal of Child Research, 7, 225238.

Hashima, P.Y. \& Amato, P.R. (1994). Poverty, social support, and parental behavior. Child Development, 65, 394-403.

Heavey, C.L., Shenk, J.L. \& Christensen, A. (1994). Marital conflict and divorce: A developmental family psychology perspective. Em L. L'Abate (Org.), Handbook of developmental family psychology and psychopathology (pp. 221-242). New York: Wiley.

Houndoumadi, A. (1996). Maternal separation anxiety and attitudes about maternal grandmother participation in child care. Early Development and Parenting, 5, 93-100.

Jennings, K.D., Stagg, V. \& Connors, R.E. (1991). Social networks and mothers' interactions with their preschool children. Child Development, 62, 966-978.

Kreppner, K. (1988). Changes in parent-child relationships with the birth of the second child. Em R. Palkovitz e M.B. Sussman (Orgs.), Transitions to Parenthood (pp. 157-181). New York: The Haworth Press.

Kreppner, K. (1991). Observation and longitudinal approach in infancy research. Em M.E. Lamb e H. Keller (Orgs.), Infant development: Perspectives from German-speaking countries (pp. 151-178). Hillsdale, NJ.: Lawrence Erlbaum.

Kreppner, K. (1992). Development in a developing context: Rethinking the family's role for the children's development. Em L.T. Winegar \& J. Valsiner (Orgs.), Children's development within social context (pp. 161-180). Hillsdale: Lawrence Erlbaum.
Kreppner, K. (1995). Padrões comportamentais da família perante um segundo filho. Em J. Gomes-Pedro \& M.F. Patricio (Orgs.), Bebé XXI: criança e família na viragem do século (pp. 431-463). Lisboa: Fundação Calouste Gulbenkian.

Kreppner, K. (1999). Transition to adolescence in two-parent and single-parent families: Differences in communication behavior in mother-adolescent dyads. Berlim: Max Planck Institute of Human Development.

Kreppner, K., Paulsen, S. \& Schuetze, Y. (1982). Infant and family development: From triads to tetrads. Human Development, 25, 373-391.

Levitt, M.J., Weber, R.A. \& Clark, M.C. (1986). Social network relationships as sources of maternal support and well-being. Development Psychology, 22, 310-316.

Lewis, M. (1987). Social development in infancy and early childhood. Em J.D. Osofsky (Org.), Handbook of infant development (pp. 419-493). New York: Wiley.

Lewis, C. (2000). A man's place in the home: Fathers and families in the UK. York: Joseph Rowntree Foundation.

Lewis, C. \& Dessen, M.A. (1999). O pai no contexto familiar. Psicologia: Teoria e Pesquisa, 15, 09-16.

Minsel, B., Fthenakis, W.E. \& Deppe, U. (1999, setembro). Changes in concept of fatherhood during child's transition to primary school. Trabalho apresentado em IXth European Conference on Development Psychology, Atenas, Grécia.

Minunchin, P. (1985). Families and individual development: Provocations from the field of family therapy. Child Development, 56, 289-302.

Minunchin, P. (1988). Relationships within the family: A systems perspective on development. Em R. Hinde \& J.S. Hinde (Orgs.), Relationships within families: Mutual influences (pp. 08-25). Oxford: Clarendon Press e University Press.

Paquette, D. (1999, setembro). Adult attachment and fathers' parental involvement. Trabalho apresentado em IXth European Conference on Development Psychology, Atenas, Grécia.

Phares, V. (1996). Fathers and developmental psychopathology. New York: Wiley.

Phares, V. \& Compas, B.E. (1992). The role of fathers in child and adolescent psychopathology: Make room for daddy. Psychological Bulletin, 111, 387-412.

Rhodes, G.L. \& Lakey, B. (1999). Social support and psychological disorder: Insights from social psychology. Em R.M. Kowalski \& M.R. Leary (Orgs.), The social psychology of emotional and behavioral problems: Interfaces of social and clinical psychology (pp. 281-339). Washington, DC: American Psychological Association.

Ribeiro, R.M., Sabóia, A.L., Branco, C.H. \& Bregman, S. (1998). Estrutura familiar: trabalho e renda. Em S.M. Kaloustian (Org.), Família brasileira: a base de tudo (pp. 135-158). Brasília, DF: Unicef/São Paulo: Cortez Editora.

Simionato-Tozo, S.M.P. \& Biasoli-Alves, Z.M.M. (1998). O cotidiano e as relações familiares em duas gerações. Cadernos de Psicologia e Educação Paidéia, 8, 137-150.

Sroufe, L.A. \& Fleeson, J. (1988). The coherence of family relationships. Em R. Hinde \& J.S. Hinde (Orgs.), Relationships within families: Mutual influences (pp. 25-47). Oxford: Clarendon Press e University Press. 
Tinsley, B.J. \& Parke, R.D. (1988). The role of grandfathers in the context of the family. Em P. Bronstein \& C.P. Cowan (Orgs.), Fatherhood today: Men's changing role in the family (pp. 236-250). New York: Wiley.

Trost, J. (1995). O processo de formação da família. Em J. Gomes-Pedro \& M.F. Patricio (Orgs.), Bebé XXI: criança e família na viragem do século (pp. 55-67). Lisboa: Fundação Calouste Gulbenkian.

Tudge, J., Hayes, S., Doucet, F., Odero, D., Kulakova, N. Tammeveski, P., Meltsas, M. \& Lee, S. (2000). Parents' participation in cultural practices with their preschoolers. Psicologia: Teoria e Pesquisa, 16, 1-11.
Uchino, B.N., Cacioppo, J.T. \& Kiecolt-Glaser, J.K. (1996). The relationship between social support and physiological processes: A review with emphasis on underlying mechanisms and implications for health. Psychological Bulletin, 119, 488531 .

Voss, H.G. (1991). A transgeracional perspective on infant development. Em M.E. Lamb \& H. Keller (Orgs.), Infant development: Perspectives from German-speaking countries (pp. 85112). Hillsdale, NJ.: Lawrence Erlbaum. 